Nig. J. Biotech. Vol. 35 (2018) 73-81

ISSN: 01891731

Available online at

http://www.ajol.info/index.php/njb/index

and www.biotechsocietynigeria.org

DOI: https://dx.doi.org/10.4314/njb.v35i1.9

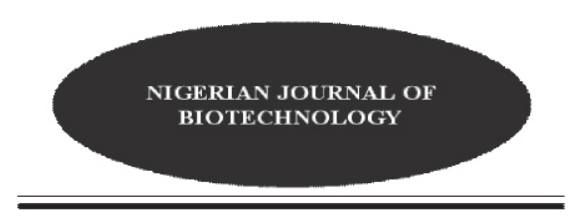

\title{
Concept of Plant Genetic Engineering towards Food Security in Africa
}

\author{
Okwuonu, I.C
}

National Root Crops Research Institute Umudike, Abia State

Copyright resides with the authors in terms of the Creative Commons License 4.0 .
(See http://creativecommons.org/licenses/by/4.0/).
Condition of use: The user may copy, distribute, transmit and adapt the work, but must recognize
the authors and the Nigerian Journal of Biotechnology.

\begin{abstract}
Modern biotechnology tools are paramount for improved and sustainable agriculture aimed at achieving food security in Africa. The continent is continually faced with the challenge of providing for its increasingly growing population amongst rapidly diminishing resources and inevitable interferences of environmental biotic and abiotic factors. It is therefore pertinent to leverage on technologies that have aided developed countries of the world to attain self-reliance. Efforts to create positive public opinion and thus alleviate fear associated with biotechnology products and GM crops require a comprehensive understanding of the concept of plant genetic engineering. This review highlights the basic concept of genetic engineering and measures taken to ensure its safety to life and the environment.
\end{abstract}

Keywords: Genetic engineering, GMO, Transgenic, Agrobacterium, Particle bombardment

\section{Introduction}

Genetic engineering and the development of genetically modified organisms (GMO) particularly for the purposes of food and feed have been the most controversial topic in the past decades (Zhang et al., 2016). Safety concerns have been centered on unknown longterm impact on human and animal health as well as the environment (Buiatti et al., 2013). However, the application of GMO technologies has recorded great achievements in the fields of agriculture (Thomson et al., 2010), medicine (Diaz \& Fridovich-Keil, 2016) and industry (Moschini, 2006). Some of these applications include genetically modified plants and animal with improved agronomical and nutritional traits and for use as bioreactors for the production of enzymes and chemicals in industry. Life-saving drugs such as insulin and other human proteins have long been produced using genetically modified microorganisms (Diaz \& Fridovich-Keil, 2016), as well as biodegradable plastics and biosensors towards tackling environmental problems (Kumar, 2012).

Agricultural productivity in terms of crop yield and quality in the past twenty years has been enhanced by modern agricultural practices and conventional breeding such as introduction of new varieties into localities with no preexistence, selection of varieties with desirable characteristics for further cultivation and hybridization of two parents with desirable characteristics to produce hybrid with improved traits (Barampuram and Zhang, 2011). Despite these achievements, demands on agricultural productivity continue to increase due to population growth, environmental deterioration, accelerated emergence of new crop and livestock diseases, continuous variation in climatic conditions and incessant need for sustainable energy. Unfortunately, the length of time required in bringing new improved varieties to farmers by traditional breeding pose as a deterrent to immediately proffering solutions to circumvent the effects of famine, hunger and poverty particularly in the developing worlds 
(Mlambo et al., 2001). Although advanced technologies such as tissue culture, marker assisted selection (MAS) and genomic selection are fast-tracking traditional breeding techniques, plant genetic and genome engineering have brought new avenues to facilitate breeding for new traits and overcoming biological barriers encountered in traditional breeding (Mba et al., 2012).

Efforts to create positive public opinion and thus alleviate fear associated with the acceptance of GM crops require a comprehensive understanding of the concept of plant genetic engineering. Sustainable agriculture and indeed food security for Africa depends greatly on the adoption of modern biotechnology tools including genetic engineering, genomics and genome editing for the advancement of agriculture in Africa. The inevitable increase in population, shortages of arable lands, emergence of new pathogens and pests for plant and animals as well as the increasing scourge of climate change demands that Africa promptly reconsiders and repositions her stand towards the acceptance, commercialization and adoption of GM crops. This review highlights the basic concept of genetic engineering and measures taken to ensure its safety to life and the environment.

\section{Impact of Plant Genetic Engineering}

Genetic engineering is the construction of recombinant DNA molecules coding for a desired trait and the subsequent integration and expression of this DNA in plants, animals or microorganisms with the intent to modify the characteristics of the target organism (Kumar, 2012). Organisms produced in this manner are referred to as genetically modified organism (GMO). Importantly, the genes of interest (GOI) transferred in this manner may not necessarily be from the same or other species, but can be sourced from completely unrelated organisms. They are thus referred to as "transgenes" (Qaim, 2009) and the resulting modified organisms as being "transgenic".

Genetically modified crops have been used commercially for more than twenty years and contributed to significant impact on the economy and general well-being of farmers and consumers, particularly in North America (Adenle, 2011). GM crops are presently grown in the United States, Canada, Argentina, Brazil, India, China, Sudan, South Africa and Burkina Faso (James, 2013). A variety of crops have been genetically transformed for a number of traits including herbicide, insect and disease resistance as well as elevated levels of nutrient content (Qaim, 2009). Examples of such genetically improved crops already commercialized include herbicide resistant (HT) soybean, HT maize, HT maize stacked with insect resistance, virus resistance papaya and Bt cotton transformed with insect resistance gene from Bacillus thuringiensis (Qaim, 2009). Many additional, genetically modified crops are undergoing field trials and some are awaiting approval for commercial release. These include $\mathrm{Bt}$ rice in China, Bt vegetables (eggplant, cauliflower and cabbage) in India, virus resistance root and tuber crops, bio-fortified rice (Golden Rice), cowpea, cassava and other root and tuber crops (James, 2011; Ruane, 2013).

Apart from crop improvement, genetically modified plants potentially provide a variety of other benefits; such as improving the health status of populations by consumption of nutritionally enhanced foods such as Golden Rice modified for elevated levels of beta-carotene, a precursor for Vitamin A (Unnevehr et al., 2007), and by the production of cost effective and easyto-manage oral vaccines derived from plants genetically modified to express such proteins. GM crops can also be applied to promote organic farming through the reduction of inputs of agrochemicals into the environment or designed for bioremediation of soils contaminated with heavy metals and toxic organic compounds (Macek et al., 2008; Brookes and Barfoot, 2012).

\section{Tools required for plant genetic engineering}

Certain tools are required for carrying out genetic transformation of an organism. Firstly, a genetic construct must be produced for carrying the genetic material intended for integration into the target genome. This consists of the gene(s) of interest conferring the desired novel trait(s), a promoter that drives expression of the gene of interest in the desired manner, and a DNA poly-A sequence that signals the end of the desired gene expression. Fused together, these components are referred to as the gene expression cassette. A DNA transfer method is then required to introduce the expression 
cassette and ensure its integration into the genome of the target organism. Because gene transfer and integration is a relatively inefficient process (usually only $1 \%$ or less of the treated cells are successfully transformed), a selectable marker is required to facilitate recovery of the successful transformation events from among the non-transgenic cells. The ability to monitor the transformation process is important in understanding the progress and pattern of transgene expression. This makes scorable or visual markers essential tools for development and application of genetic transformation technologies for a given organism. Finally, a target tissue is required into which the new DNA can be effectively integrated. If a whole new transgenic organism such as a plant is to be recovered, then the target tissue should be totipotent in nature, being both amenable to receiving the foreign DNA, and after the selection process, to regenerate into a whole organism expressing the novel trait.

Target tissues employed to date include organogenic callus, embryogenic callus, apical shoots, axillary buds, embryogenic leaflets, flowers, immature embryos and in vitro shoots (Barampuram and Zhang, 2011). Both transformation efficiency and regeneration of transgenic events from these target materials depends on the plant type, method of DNA transfer and amenability of these tissues to tissue culture processes.

Selectable marker genes used for selection of putative transgenic events include geneticin ( $\mathrm{Li}$ et al., 1996) and paramomycin coded by the nptII gene (Siritunga and Sayre, 2003; Ihemere et al., 2006), hygromycin coded by $h p t$ gene (Bull et al., 2009), phosphinitricin and basta coded by the bar gene (Sarria et al., 2000) and mannose coded by phosphomannose isomerase (Zhang et al., 2000; Ihemere et al., 2003).

Promoters are usually placed directly upstream of a gene coding region and contain specific sequences that are recognized by regulatory proteins involved in the initiation of transcription (Peremarti et al., 2010). These could be constitutive, inducible, tissue specific and developmental stage specific promoters. The cauliflower CaMV 35S promoter (Peremarti et al., 2010; Liu et al., 2011) has been widely applied in plant transformation.
Visual marker genes employed in plant genetic transformation systems to date include $\beta$-glucuronidase (GUS), , firefly luciferase (LUC), green fluorescent protein (GFP) and red fluorescent protein (Okwuonu et al., 2015). Fluorescent proteins are mostly preferred as their detection and monitoring are nondestructive, allowing continuous monitoring of the same putative transgenic cells and tissues over time and across developmental process at both the tissue culture and whole plant stages .

\section{Genetic transformation methods}

There are basically two DNA transfer methods employed in the production of transgenic plants; referred to as indirect and direct DNA transfer processes (Narusaka et al., 2012). Indirect DNA transfer involves the use of bacteria such as Agrobacterium tumefaciens or Agrobacterium rhizogenes to transfer foreign DNA into plant cells, while direct DNA transfer utilizes physical or chemical methods of transferring foreign genes into the plant cell. Direct DNA transfer methods include particle bombardment, electroporation, polyethylene glycol, siliconcarbide whiskers and liposome-mediated transformation techniques.

Agrobacterium-mediated transformation entails the use of non-virulent strains of $A$. tumefaciens or $A$. rhizogenes to mediate the transfer of foreign DNA through the cell wall and into the nucleus. In their virulent forms these bacteria are the causative agents of "crown gall disease" and "hairy root disease" respectively. The bacteria are able to produce their respective disease conditions due to the presence of a large $\mathrm{Ti}$ (tumor-inducing) plasmid in A. tumefasciens and a $\mathrm{Ri}$ (root-inducing) plasmids in $A$. rhizogenes. Both Ti- and Ri- plasmids carry a form of "T-DNA" (transferred DNA) that contains genes responsible for producing the disease conditions. The T-DNA element is flanked by two 25-bp direct repeats called the left border (LB) and right border (RB), respectively, which act as the signal for initiation and termination of the TDNA transfer process (Zupan et al., 2000). The tumor and root inducing genes have been removed by researchers by genetically engineering Agrobacterium strains so that they can no longer cause disease. Genes of interest 
to the researchers can then be carried on a binary plasmid that is introduced into and replicated by the bacterial cell. Agrobacteriummediated transformation is preferred due to its ability to transfer relatively large, intact segments of DNA, producing plants with simple, stable and low copy number transgene insertions (Barampuram and Zhang, 2011).

Microparticle bombardment is a direct DNA transfer method often referred to as biolistics. This requires a gene gun and involves the use of micron-sized micro-projectile particles such as gold and tungsten which are coated with the desired DNA and accelerated to deliver the DNA directly through the cell wall and into the nucleus of a target cell (Rivera et al., 2014). Particle bombardment-mediated transformation has the ability to successfully transfer multiple, independent transgene expression cassettes into target tissues and has been achieved in many crop plants including wheat, rice and soybeans (Campbell et al., 2000; Agrawal et al., 2005; Schmidt et al., 2005). Particle bombardment-mediated transformation is often associated with low transformation efficiency (Rivera et al., 2012).

\section{Genome editing}

Genome editing is the alteration of specific DNA sequences in the genome of an organism with the aim of producing a permanent heritable change (Mundembe, 2013). Genome editing facilitates gene targeting (GT) at a specific gene locus. Conventional transgenic technologies rely on random integration of foreign DNA into the plant genome through illegitimate recombination succeeding a double stranded break which results to small insertions and deletions. With random transgene integration, the integration site, gene copy number as well as the organization of the transgene at the site of integration cannot be intentionally controlled by the researcher. This is essential as the level, pattern and stability of transgene expression is greatly influenced by the transgene integration site (Kumar et al., 2006).

Gene editing ensures predictable and precise integration of DNA into the plant genome at pre-determined loci (Puchta \& Fauser, 2013). The transgene(s) can be precisely integrated at a specified locus through homologous recombination (HR) between the target and incoming donor DNA, flanked with sequences sharing homology with the target sequence. Locations that could trigger chromosomal positional effects, or produce unwanted effect in the transgene could be avoided with HR. Specific genome alteration is achieved by artificially inducing a double stranded break and taking advantage of the natural repair DNA mechanisms to introduce small defined changes or whole piece of DNA coding for a specific trait can be inserted at the break site by HR (Townsend et al., 2009). This process has been used in restoring defective gene function both at an engineered site and at an endogenous locus. In addition, gene editing unlike conventional transformation has the potential to completely knock-out the expression of existing genes or make specific changes in their gene function by targeting control elements such as promoter sequences (Puchta \& Fauser, 2013).

Genome editing tools developed in the last decade include zinc finger nuclease (ZFN), Transcription activator-like effector nuclease (TALENS) and the clustered regularly interspaced short palindromic repeat (CRISPR/Cas9) systems (Putcha and Fauser, 2013). These systems are characterized of a non-specific nuclease domain fused to a specific DNA recognition domain. For ZFN, transcriptionlike factor zinc finger proteins with DNA recognition specificity are fused to Fok 1 endonuclease, which initiates a double stranded DNA break when present as a dimer. ZFNs has been successfully employed for GT in whole animals and cell lines, in Drosophila (Beumer, 2006), zebrafish (Meng, 2008) and human cell lines (Weinthal et al., 2010). TALENS is a pathogen based transcriptional factor consisting of 13 to 28 copies of highly conserved repeats spanning 34 amino acids each (Putcha and Fauser, 2013). The DNA binding domains are fused to Fok 1 endonucleases as for ZFNs. The use of TALENS for the introduction of targeted mutation has been demonstrated by both $\mathrm{Li}$ et al., 2012 and Voytas, 2013. The CRISPR/Cas9 system consists of a bacterial endonuclease Cas 9 directed by sequence-specific RNA molecule. This system can be redirected to different target sites simply by modifying the sequence of a single synthetic chimeric RNA guide (sgRNA or crRNA:tracr RNA). The application of this technique has been demonstrated in different 
eukaryotes including plants ( $\mathrm{Li}$ et al., 2012; Putcha and Fauser, 2013).

\section{Transgenic Analysis}

Putative transgenic events are subjected to batteries of molecular analysis to ascertain the integration of the desired gene, copy number of gene inserted, level of gene expression and types of protein produced, including allergens (Taylor et al., 2012). The presence of the transgene in the target genome is easily determined by means of polymerase chain reaction (PCR) using gene specific primers while copy number of genes inserted is determined by nucleic acid hybridization methods such as Dot blot and Southern blot analysis using specific probes produced with sequences of the targeted gene. Gene expression levels can be determined by Northern blot analysis or reverse transcriptase polymerase chain reaction (RTPCR) while protein expression is determined by Western blot analysis.

Intact genomic DNA extracted from tissues of recovered transgenic lines such as leaves, roots, shoots and stem are used in PCR, Dot blot and Southern blot analysis. Various PCR kits containing master mixes of enzymes and buffers are readily available in the market and are reacted with genomic DNA derived from plant samples in the presence of gene specific primers. The reaction mixture is set up in thermocycler at conditions determined empirically for the amplification of the target gene. For transgene integration and copy number detection, genomic DNA derived from plant samples are separated by gel electrophoresis and embedded in nitrocellulose paper which is then treated with gene specific probe. Hybridization of probe with DNA sequence confirms integration while the number of bands observed shows the number of gene copies integrated.

High quality RNA and protein samples extracted from recovered transgenic plants are used for detection of gene and protein expression levels, respectively. The RNA and protein molecules separated by gel electrophoresis are embedded on nitrocellulose paper and treated with specific probes in Northern and Western blot nucleic acid hybridization assay while for RT-PCR, the RNA is reversed back to DNA in reverse transcriptase reaction and then is treated with specific primers to show gene expression.

\section{Phenotypic Analysis}

Phenotypes of the recovered events are also considered with those with unexpected phenotypes eliminated from the pipeline. Events with low copy number (1-2) gene copy, high expression of transgene with no detectable variation in phenotype are further evaluated for the desired trait and phenotypic impact of the transgene in the greenhouse under much regulated environmental conditions such as light intensity, temperature, humidity and photoperiod.

Events showing high expression of the desired trait with no variation in phenotype are further advanced to confined field trial (CFT) to ascertain performance in the open field as well as its impact in the environment. Such events are evaluated in a confined field site, excluded from fields bearing same type of crop to prevent gene flow. Animal and unauthorized persons are also barred from entering the site in other to ensure strict compliance to regulatory requirement.

\section{Biosafety policies and Regulations}

In order to ensure personal, public and environmental safety in the handling and release of GM crops, biosafety laws and regulatory agencies enforcing these laws are mandatory in countries intending to engage in transgenic research and the production of GM crops. This entails adherence to containment principles, practices and technologies in preventing unintentional exposure and release of pathogen, toxins, genetic materials, hazardous chemicals and radiation to the environment (Kumar, 2012). This fundamentally involves the enactment of Biosafety laws by individual countries in line with the Codex guidelines and institutionalization of governing agencies that will implement these laws. Mostly, awareness creation among researchers and the public to biological safety at the grass root is paramount (Kumar, 2012).

Biosafety requirement for transgenic research in most countries requires the accreditation of institutions by the Biosafety Management Agencies. Institutions involved in dealing with GMO are expected to have in place well contained laboratories with trained personnel and limited access to unauthorized 
persons. A biosafety level II screen house and confined field trial sites are also necessities in such institutions. Additionally such institutions comprise of local biosafety committees within the institutions to ensure compliance to the biosafety rules and regulations by the staff involved in the research. Series of molecular analysis are carried out to determine the behavior of the transgene in terms of integration, stability, expression and phenotypic impact on the target organisms. Putative transgenic event showing abnormal tendency are negatively selected right from the laboratory and are not considered as candidates for field trials nor for product development.

Several molecular biology tools are available to provide sensitive detection methods at both DNA and protein levels to ensure the traceability of transgenes in GM crops. Labeling of GM crops or/and their product is required if the GMO content of the item exceeds the recommended threshold (Kamle \& Ali, 2013).

\section{Conclusion}

GM crops are the most regulated crops worldwide. In the United States alone, three independent agencies, the Environmental Protection Agency (EPA), the Food and Drug Administration (FDA) and the U.S. Department of Agriculture (USDA) each regulating transgenic crops from different perspectives (US library of congress, 2014). More so, several independent studies have been carried out by governmental, scientific and medical organizations worldwide towards ascertaining the safety of these products since the first commercialization of GM crops in the early 80s. None of these studies did attribute any hazardous claim to GM technology contrarily to public opinion (NAS, 2004, AAAS, 2012). This review has described in brief the fundamental principles and practices involved in the development of GM crops to enhance understanding and appreciation of the technology by all stakeholders.

\section{References}

Adenle, A. A. (2011). Global capture of crop biotechnology in developing world over a decade. J Genet Eng Biotechnol. 9(2): 83 - 90.

Agrawal, P.K., Kohli, A., Twyman, R.M., and
Christou, P. (2005). Transformation of plants with multiple cassettes generates simple transgene integration patterns and high expression levels. Mol. Breed. 16: 247-260.

Barampuram, S., \& Zhang, Z. J. (2011). Recent advances in plant transformation. In Plant Chromosome Engineering.Humana Press., Pp. 1 $-35$.

Beumer, K., Bhattacharyya, G., Bibikova, M., Trautman, J. K., \& Carroll, D. (2006). Efficient gene targeting in Drosophila with zinc-finger nucleases. Genetics, 172(4): 2391 - 2403.

Brookes, G., \& Barfoot, P. (2012). GM crops: global socio-economic and environmental impacts 1996-2010. PG Economics Ltd. http://www. pgeconomics. co. uk/page/33/global-impact-2012 [accessed 31 Jan 2013].

Buiatti, M., Christou, P., \& Pastore, G. (2013). The application of GMOs in agriculture and in food production for a better nutrition: Two different scientific points of view. Genes Nutr, 8(3): 255-270. http://doi.org/10.1007/s12263-0120316-4

Bull, S. E., Owiti, J. A., Niklaus, M., Beeching, J. R., Gruissem, W., \& Vanderschuren, H. (2009). Agrobacterium-mediated transformation of friable embryogenic calli and regeneration of transgenic cassava. Nat Protoc, 4(12): 18451854.

Campbell, B. T., Baeziger, P. S., Mitra, A., Sato, S., and Clemente, T. (2000) Inheritance of multiple genes in wheat. Crop Sci. 40: 1133-1141.

Diaz, J., \& Fridovich-Keil, J. (2016). Genetically modified organism (GMO) - GMOs in medicine and research. Encyclopedia Britannica. Retrieved $\mathrm{f} \quad \mathrm{r} \quad \mathrm{m}$ https://www.britannica.com/science/genetically -modified-organism/GMOs-in-medicine-andresearch

Finer, J. J., Beck, S. L., Buenrostro-Nava, M. T., Chi, Y. T., \& Ling, P. P. (2006). Monitoring Gene Expression. In Plan Tissue Culture Engineering. Springer Netherlands. Pp. 31 - 46. 
Ihemere, U., Arias-Garzon, D., Lawrence, S., \& Sayre, R. (2006). Genetic modification of cassava for enhanced starch production. Plant Biotechnol J, 4(4): 453 - 465.

Jach, G., Binot, E., Frings, S., Luxa, K., \& Schell, J. (2001). Use of red fluorescent protein from Discosoma sp.(dsRED) as a reporter for plant gene expression. Plant J, 28(4): 483 491.

James, C. (2011). ISAAA Brief 43, Global Status of Commercialized Biotech/GM Crops: 2011. ISAAA Briefs. Ithaca, New York: International Service for the Acquisition of Agri-biotech Applications (ISAAA). Cited December, 23, 2013.

James, C. (2013). Global status of commercialized biotech/GM crops: 2010. Ithaca; USA: International Service for the Acquisition of Agri-biotech Applications (ISAAA).

Kamle, S., and Ali, S. (2013). Genetically modified crops: Detection strategies and biosafety issues. J.gene 522: 123 - 132. http://doi.org/10.1016/j.gene.2013.03.107

Kumar, S., Franco, M., \& Allen, G. C. (2006). Gene targeting: development of novel systems for genome engineering in plants. Floriculture, ornamental and plant biotechnology: advances and topical issues. Global Science Books., Pp. 84 $-98$.

Kumar, S. (2012). Biosafety issues in laboratory research. Biosafety 1: e116.

Li, H.-Q., Sautter, C., Potrykus, I., \& PuontiKaerlas, J. (1996). Genetic transformation of cassava (Manihot esculenta Crantz), Nat Biotechnol. 14: 736-740.

Li, T., Liu, B., Spalding, M. H., Weeks, D. P., \& Yang, B. (2012). High-efficiency TALEN-based gene editing produces disease-resistant rice. Nat Biotechnol. 30(5): 390 - 392.

Liu, J., Zheng, Q., Ma, Q., Gadidasu, K. K., \& Zhang, P. (2011). Cassava Genetic Transformation and its Application in BreedingF. J Integr Plant Biol, 53(7): 552 - 569.
Macek, T., Kotrba, P., Svatos, A., Novakova, M., Demnerova, K., \& Mackova, M. (2008). Novel roles for genetically modified plants in environmental protection. Trends Biotechnol, 26(3): $146-152$.

Mba, C., Guimaraes, E. P., \& Ghosh, K. (2012). Re-orienting crop improvement for the changing climatic conditions of the 21st century. Agriculture \& Food Security, 1(1), 7. http://doi.org/10.1186/2048-7010-1-7

Meng, X., Noyes, M. B., Zhu, L. J., Lawson, N. D., \& Wolfe, S. A. (2008). Targeted gene inactivation in zebrafish using engineered zinc-finger nucleases. Nat Biotechnol. 26(6): 695 - 701.

Mlambo, S. S., \& McCarter, S. B. Session I: Impact of genetic engineering on agriculture. Virus, 1(35): 1 - 6.

Moschini, G. (2006). Pharmaceutical and Industrial Traits in Genetically Modified Crops?: Co-existence with Conventional Agriculture. Am J Agric Econ. 88(5): 1184-1192, https://doi.org/10.1111/j.14678276.2006.00931.x

Mundembe, R. (2013). Gene Targeting and Genetic Transformation of Plants. In Genetic Engineering. InTech. Pp. 49 - 59.

Narusaka, Y., Narusaka, M., Iwabuchi, M., \& Yamasaki, S. (2012). Methods to Transfer Foreign Genes to Plants. InTech .Pp.173-188.

Nyaboga, E., Njiru, J., Nguu, E., Gruissem, W., Vanderschuren, H., \& Tripathi, L. (2013). Unlocking the potential of tropical root crop biotechnology in east Africa by establishing a genetic transformation platform for local farmerpreferred cassava cultivars. Front Plant Sci, 4:526

Okwuonu, I.C., Achi, O.K., Egesi, C.N. and Taylor, N.J., 2015. Evaluation of red fluorescent protein (DsRed) as alternative visual marker of genetic transformation in cassava (Manihot esculenta Crantz). In Vitro Cell Dev Biol Plant. 51(5): 571 579. 
Peng Zhang (2000). Studies on cassava (Manihot esculenta Crantz) transformation: towards genetic improvement. A dissertation submitted to the Swiss Federal Institute of Technology Zürich for the degree of Doctor of Natural Sciences

Peremarti, A., Twyman, R. M., Gómez-Galera, S., Naqvi, S., Farré, G., Sabalza, M., ... \& Capell, T. (2010). Promoter diversity in multigene transformation. Plant Mol Biol, 73(4-5): 363 378.

Petersen, W., Umbeck, P., Hokanson, K., \& Halsey, M. (2005). Biosafety considerations for selectable and scorable markers used in cassava (Manihot esculenta Crantz) biotechnology. Environ Biosafety Res, 4(02): 89 - 102.

Porteus, M. H. (2009). Plant biotechnology: zinc fingers on target. Nature, 459(7245): 337 - 338.

Puchta, H., \& Fauser, F. (2013). Gene targeting in plants: 25 years later. Int. J. Dev. Biol, 57: 629 637.

Qaim, M. (2009). The economics of genetically modified crops. Annu. Rev. Resour. Econ., 1(1): $665-694$.

Que, Q., Chilton, M. D. M., de Fontes, C. M., He, C., Nuccio, M., Zhu, T., ... \& Shi, L. (2010). Trait stacking in transgenic crops: challenges and opportunities. GM crops, 1(4): 220-229.

Rivera, A. L., Magaña-Ortíz, D., Gómez-Lim, M., Fernández, F., \& Loske, A. M. (2014). Physical methods for genetic transformation of fungi and yeast. Phys Life Rev. 11(2):184 - 203.

Ruane, J. (2013). An FAO e-mail conference on GMOs in the pipeline in developing countries: The moderator's summary. In FAO.[online] Retrieved [2013-09-19] from: http://www. fao. org/biotech/biotech-forum.

Sarria, R., Torres, E., Angel, F., Chavarriaga, P., \& Roca, W. M. (2000). Transgenic plants of cassava (Manihot esculenta) with resistance to Basta obtained by Agrobacterium-mediated transformation. Plant Cell Rep. 19(4): 339 - 344.

Schmidt, M. A., Tucker, D. M., Cahoon, E. B., \&
Parrott, W. A. (2005). Towards normalization of soybean somatic embryo maturation. Plant Cell Rep. 24(7): 383 - 391.

Siritunga, D., \& Sayre, R. T. (2003). Generation of cyanogen-free transgenic cassava. Planta, 217(3):367 - 373.

Taylor, N., Gaitán-Solís, E., Moll, T., Trauterman, B., Jones, T., Pranjal, A., ... \& Fauquet, C. M. (2012). A high-throughput platform for the production and analysis of transgenic cassava (Manihot esculenta) plants. Trop Plant Biol. 5(1):127 - 139.

Thomson, J. A.; Shepherd, D. N.; Mignouna, H. D. (2010). Developments in agricultural biotechnology in Sub-Saharan Africa. AgBioForum, 13: 314-319.

Townsend, J. A., Wright, D. A., Winfrey, R. J., Fu, F., Maeder, M. L., Joung, J. K., \& Voytas, D. F. (2009). High-frequency modification of plant genes using engineered zinc-finger nucleases. Nature. 459(7245):442 - 445.

Twyman, R. M. (2003). Growth and development: control of gene expression, regulation of transcription. In: Thomas $B$, Murphy DJ, Murray B (eds) Encyclopedia of Applied Plant Sciences. Elsevier Science, London, p.558-567

Unnevehr L, Pray C, Paarlberg R. (2007). Addressing micronutrient deficiencies: alternative interventions and technologies. AgBioForum 10:124-34

US Library of Congress. (2014). Restrictions on Genetically Modified Organisms: United States | Law Library of Congress. Retrieved from http://www.loc.gov/law/help/restrictions-ongmos/usa.php

Voytas, D. F. (2013). Plant genome engineering with sequence-specific nucleases. Annu Rev Plant Biol. 64: 327 - 350.

Weinthal, D., Tovkach, A., Zeevi, V., \& Tzfira, T. (2010). Genome editing in plant cells by zinc finger nucleases. Trends Plant Sci. 15(6): 308 321. 
Wu, F. (2006). Mycotoxin reduction in Bt corn: potential economic, health, and regulatory impacts. Transgenic Res, 15(3): 277-289.

Zhang, C., Wohlhueter, R., \& Zhang, H. (2016). Genetically modified foods: A critical review of their promise and problems. Food Science and Human Wellness, 5(3), 116-123. https://doi.org/10.1016/j.fshw.2016.04.002.
Zupan, J., Muth, T. R., Draper, O., \& Zambryski, P. (2000). The transfer of DNA from Agrobacterium tumefaciens into plants: a feast of fundamental insights. Plant J. 23(1): 11 - 28.

Zhang, P., Potrykus, I., \& Puonti-Kaerlas, J. (2000). Efficient production of transgenic cassava using negative and positive selection. Transgenic Res, 9(6): 405 - 415. 